Open Access: ISSN: 1848-7718

Original scientific paper

\title{
The intrinsic aqueous solubility of indomethacin
}

John Comer ${ }^{1 *}$, Sam Judge ${ }^{1}$, Darren Matthews ${ }^{1}$, Louise Towes ${ }^{1}$, Bruno Falcone ${ }^{2}$, Jonathan Goodman ${ }^{2}$ and John Dearden ${ }^{3}$

${ }^{1}$ Sirius Analytical Ltd., Forest Row, West Sussex RH18 5DW, UK

${ }^{2}$ Unilever Centre for Molecular Informatics, Department of Chemistry, University of Cambridge, Lensfield Road, Cambridge CB2 1EW, UK

${ }^{3}$ School of Pharmacy \& Biomolecular Sciences, Liverpool John Moores University, Byrom Street, Liverpool L3 $3 A F$, UK

*Corresponding Author: E-mail: John.Comer@sirius-analytical.com; Tel.: +44 1342820720

Received: February 19, 2014; Revised: April 01, 2014; Published: April 01, 2014

\begin{abstract}
A value of $8.8 \mu \mathrm{g} / \mathrm{mL}$ was measured for the intrinsic solubility of indomethacin. Evidence of a form with a solubility of about $77 \mu \mathrm{g} / \mathrm{mL}$ was also obtained. Solubility measurements were conducted using the CheqSol and Curve Fitting methods using a maximum $\mathrm{pH}$ of 9. It is also demonstrated that a published intrinsic solubility of $410 \mu \mathrm{g} / \mathrm{mL}$ was in error due to decomposition of indomethacin at $\mathrm{pH}$ 12. The decomposition of indomethacin at $\mathrm{pH} 12$ was investigated. Decomposition products comprising $p$ chlorobenzoic acid and 5-Methoxy-2-methyl-3-indoleacetic acid were isolated and characterised.
\end{abstract}

Keywords: Indomethacin, solubility, CheqSol, $p$-chlorobenzoic acid, decomposition

\section{Introduction}

Indomethacin is a widely-used non-steroidal anti-inflammatory drug (NSAID), despite its propensity to cause gastric irritation and ulceration. Its structure is shown in Figure 1. Indomethacin can exist in several polymorphic solid forms and as an amorphous solid. Yamamoto [1] reported in 1968 that he had isolated three polymorphs, $\alpha, \beta$ and $\gamma$, with slightly different melting points. Borka [2] and Lin [3] claimed to have found at least four polymorphic modifications. Other authors recognise only the $\alpha$ and $\gamma$ polymorphs [4-6]. The polymorphism is believed to arise from different orientations between the aromatic indole and phenyl rings [7]. Solvates are also known to exist $[2,8]$.<smiles>COc1ccc2c(c1)c(CC(=O)O)c(C)n2C(=O)c1ccc(Cl)cc1</smiles>

indomethacin<smiles>COc1ccc2[nH]c(C)c(CC(=O)O)c2c1</smiles>

1

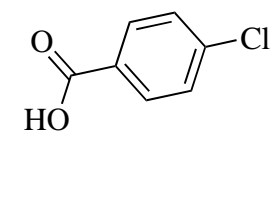

$p$-chlorobenzoic acid

Figure 1. Decomposition of indomethacin into 5-methoxy-2-methyl-3-indoleacetic acid (1) and $p$-chlorobenzoic acid at $\mathrm{pH} 12$. 
One difficulty associated with the measurement of the solubility of indomethacin is that the measured solubility can change with over time $[2,10,11]$, suggesting that there is conversion from one form to another. For example, Murdande et al. [10] found that amorphous indomethacin in aqueous solution changed almost completely to a mixture of the $\alpha$ and $\gamma$ polymorphs over a 40-minute period, with solubility decreasing from about $26 \mu \mathrm{g} / \mathrm{mL}$ to about $9 \mu \mathrm{g} / \mathrm{mL}$.

Numerous measurements of the aqueous solubility of indomethacin have been reported and results are presented in Table 1. Predicted indomethacin solubilities from a number of commercial and free-to-use software programs are also summarised in Table 1.

It can be seen from Table 1 that the published solubilities for the $\alpha$ and $\gamma$ polymorphs are quite consistent. It is, however, difficult to say with assurance whether the so-called polymorph I is the $\alpha$ or $\gamma$ polymorph, and polymorphs II and IV are not obviously either $\alpha$ or $\gamma$.

Table 1. Reported measured values for the solubility of indomethacin, and a selection of values calculated by commercial software. $\mathrm{RT}=$ room temperature; $\mathrm{n} / \mathrm{a}=$ not available.

Measured values

\begin{tabular}{|c|c|c|c|}
\hline Form & $\mu \mathrm{g} / \mathrm{mL}$ & Temp. ${ }^{\circ} \mathrm{C}$ & REF. \\
\hline polymorph I & 4.2 & 25 & 2 \\
\hline polymorph II & 15.6 & 25 & 2 \\
\hline polymorph IV & 20 & 25 & 2 \\
\hline$\alpha$ polymorph & 8.7 & 35 & 4 \\
\hline Y polymorph & 6.9 & 35 & 4 \\
\hline Y polymorph & 5 & 25 & 9 \\
\hline amorphous & 22.5 & 25 & 9 \\
\hline Y polymorph & 5 & 25 & 10 \\
\hline amorphous & 24.5 & 25 & 10 \\
\hline$\alpha$ polymorph & 9.4 & 35 & 12 \\
\hline Y polymorph & 6.9 & 35 & 12 \\
\hline polymorph I & 9.1 & 25 & 13 \\
\hline polymorph II & 14.4 & 25 & 13 \\
\hline$\alpha$ polymorph & 4 & $\mathrm{n} / \mathrm{a}$ & 14 \\
\hline Y polymorph & 6 & $\mathrm{n} / \mathrm{a}$ & 14 \\
\hline amorphous & 10 & $\mathrm{n} / \mathrm{a}$ & 14 \\
\hline
\end{tabular}

\begin{tabular}{c|r|c|c} 
Form & $\mu \mathrm{g} / \mathrm{mL}$ & Temp. $^{\circ} \mathrm{C}$ & REF. \\
\hline unspecified & 9.5 & $\mathrm{RT}$ & 15 \\
\hline unspecified & 0.94 & 25 & 16 \\
\hline unspecified & 18.5 & 25 & 17 \\
\hline unspecified & 25.3 & 35 & 17 \\
\hline unspecified & 3.9 & 25 & 18 \\
\hline unspecified & 2.3 & 25 & 19 \\
\hline unspecified & 40 & 25 & 20 \\
\hline unspecified & 15 & 25 & 21 \\
\hline unspecified & 27.1 & $\mathrm{RT}$ & 22 \\
\hline unspecified & 410 & 25 & 25 \\
\hline unspecified & 0.94 & 25 & 31 \\
\hline unspecified & 1.16 & 25 & 35 \\
\hline unspecified & 3.09 & 25 & 36 \\
\hline unspecified & 0.4 & 25 & 37 \\
\hline unspecified & $<1$ & $\mathrm{RT}$ & 38 \\
& & &
\end{tabular}

Because amorphous solids do not have crystal lattices in which molecules can be held strongly, they are more soluble and are lower-melting than are their crystalline forms. Murdande et al. [10] reported that the aqueous solubility ratio (amorphous/ $\gamma$-polymorph) for indomethacin was 4.9. Borka [2] found the amorphous form of indomethacin to have a melting point of $55-57^{\circ} \mathrm{C}$, in contrast to values ranging from 134 to $160^{\circ} \mathrm{C}$ for various polymorphic forms.

There is considerable variation among the unspecified form solubilities reported, which could indicate that different proportions of polymorphs and amorphous form have contributed to the reported solubilities.

One reported solubility value, $(410 \mu \mathrm{g} / \mathrm{mL})$, is significantly higher than all the others and has been the source of some controversy [23]. This result was one of 132 measured by the Sirius CheqSol method and cited in the Cambridge Solubility Challenge. The Cambridge Solubility Challenge invited readers to use 100 measured solubility values to train software for predicting solubility from the structure alone [24], and then 
to use the trained software to predict the solubility of a further 32 molecules whose solubilities had been withheld from the publication. One of these 32 molecules was indomethacin. A total of 99 entries were received from software providers, and the results were reviewed in a subsequent publication [25]. Although most of the 32 values were predicted well, software was not able to predict the solubility of indomethacin.

In the current paper we used the CheqSol approach to reinvestigate the aqueous solubility of indomethacin and determined a value of $8.8 \mu \mathrm{g} / \mathrm{mL}$. We also found evidence suggesting an amorphous form, as well as evidence to suggest that indomethacin might have decomposed during the measurement reported in [25]. We used NMR and HPLC to characterise the decomposition, which occurs at high $\mathrm{pH}$. The results reported in this paper together with the graphical representations of dissolution and precipitation events during the experiments enable us to gain improved understanding of the solubility of indomethacin.

\section{Experimental}

Indomethacin (17378, $\geq 99 \%$ ) was purchased from Sigma Life Science and used without further purification. The polymorphic form of this material was not specified. Solubility and $\mathrm{p} K_{\mathrm{a}}$ values were measured using the SiriusT3 automatic titration system (Sirius Analytical Ltd., Forest Row, UK), using the software supplied with the instrument to calculate results from the experimental data. Solubility experiments to prepare solid material for HPLC and NMR studies were undertaken on the Sirius GLpKa automatic titration system. Solution and solid composition were investigated using NMR spectroscopy, LCMS and HPLC with UV detection. NMR spectral data (500 MHz ${ }^{1} \mathrm{H} N M R$ and $125 \mathrm{MHz}{ }^{13} \mathrm{C}$ ) were recorded in a BRUKER Avance $500 \mathrm{MHz}$ BroadBand. ${ }^{1} \mathrm{H}$ and ${ }^{13} \mathrm{C}$ NMR chemical shifts are reported in parts per million (ppm) and referenced relative to their residual solvent peaks. Assignments were determined by unambiguous chemical shift, analogue comparison, coupling patterns, or HMQC experiments. LCMS data were collected with a Waters ZQ Mass Spectrometer using Electrospray lonisation, connected to a Waters $2795 \mathrm{HPLC}$ and 996 DAD. The column used was an Agilent Poroshell $120 \mathrm{C}-184.6 \times 30 \mathrm{~mm}, 2.7 \mu \mathrm{m}$ particle size, and the solvent mixtures were A: $10 \mathrm{mM}$ ammonium acetate with $0.1 \%$ formic acid, and B: $95 \%$ aqueous acetonitrile with $0.05 \%$ formic acid. HPLC/UV data were collected with a Shimadzu SPD M-20A PDA connected to a Shimadzu LC-10 HPLC. The column used was a Phenomenex KinetexC-18 $4.6 \times 50 \mathrm{~mm}$, $2.6 \mu \mathrm{m}$ particle size, and the solvent mixtures were A: $0.1 \%$ formic acid, and B: acetonitrile.

Solubility measurements were carried out using the CheqSol and Curve Fitting methods. These methods and the associated Bjerrum Curves are described in detail elsewhere [26-28]. Indomethacin samples of around $2 \mathrm{mg}$ were weighed accurately into glass vials. Measurements were performed in $1.5 \mathrm{~mL}$ of deionised water. The $\mathrm{pH}$ of the prepared sample was raised by adding standardised $0.5 \mathrm{M} \mathrm{KOH}$ solution, under which conditions all the indomethacin dissolved in ionised form. The transmission of light through the sample was monitored at $500 \mathrm{~nm}$ by use of a spectroscopic dip probe connected to a diode array spectrophotometer. The spectroscopic data were used to detect the onset of precipitation as the $\mathrm{pH}$ was lowered by adding standardised $0.5 \mathrm{M} \mathrm{HCl}$ solution. In CheqSol assays, small aliquots of $\mathrm{KOH}$ or $\mathrm{HCl}$ solution were added after precipitation to maintain the system close to equilibrium, and solubility results were calculated from rates of $\mathrm{pH}$ change vs. concentration. In Curve Fitting assays, only $\mathrm{HCl}$ was added, and solubility was calculated by fitting a Precipitation Bjerrum Curve to the data. Some Curve Fitting experiments commenced at low $\mathrm{pH}$; these are discussed later.

In order to calculate solubility results from the CheqSol and Curve Fitting data the $\mathrm{p} K_{\mathrm{a}}$ of indomethacin is required, and a value of $4.13 \pm 0.018, \mathrm{I}=0.058 \mathrm{M}, 25.2{ }^{\circ} \mathrm{C}$ was measured in triplicate by a UV-metric method 
on the same instrument. Some comment is required on this $\mathrm{p} K_{\mathrm{a}}$ measurement. $\mathrm{A} \mathrm{pH}$-metric titration method is often chosen to measure the $\mathrm{p} K_{\mathrm{a}}$ of compounds in which the ionisable group shows weak UV activity. However it proved to be surprisingly difficult to measure the $\mathrm{p} K_{\mathrm{a}}$ reliably by the $\mathrm{pH}$-metric method. Because of its low aqueous solubility, indomethacin $\mathrm{p} K_{\mathrm{a}}$ must be measured in cosolvent-water mixtures and an aqueous result obtained by extrapolation. This was first attempted in methanol-water solutions adjusted to an ionic strength of $0.15 \mathrm{M}$ with $\mathrm{KCl}$. A result of 4.20 was obtained from the Yasuda-Shedlovsky extrapolation of four $\mathrm{p}_{\mathrm{s}} K_{\mathrm{a}}$ values measured at methanol percentages between $37.4 \%$ and $52.7 \%$. However a further 14 methanol-water $p_{s} K_{a}$ values were considered to be too unreliable to include in the extrapolation, and confidence in the methanol-water result was low. Measurement was then attempted in solutions containing dioxane-water adjusted to an ionic strength of $0.15 \mathrm{M}$ with $\mathrm{KCl}$. A result of 4.22 was obtained from the Yasuda-Shedlovsky extrapolation of seven $\mathrm{p}_{\mathrm{s}} K_{\mathrm{a}}$ values measured at dioxane percentages between $37.4 \%$ and $52.7 \%$. This value was used in the Curve Fitting solubility measurement made from low to high pH (Figure 2). However the linear extrapolation of the same data yielded a result of 3.60 and the discrepancies between these two dioxane-water extrapolations led to some caution. It has been reported that indomethacin can self-aggregate in pure water and in the absence of ionic strength [29], and it seems likely that this tendency will be stronger at high ionic strength. This tendency for aggregation was not allowed for in the software used in the SiriusT3 to calculate $\mathrm{p} K_{\mathrm{a}}$ values from titration data, and this could lead to errors in $\mathrm{p} K_{\mathrm{a}}$ measurement. The behaviour of indomethacin during $\mathrm{pH}-\mathrm{metric} \mathrm{p} K_{\mathrm{a}}$ measurement at $1 \mathrm{mM}$ concentration when forming aggregates in the presence of $0.15 \mathrm{M} \mathrm{KCl}$ and varying percentages of solvent is likely to be hard to predict. The difficulty of accounting for aggregation might also explain why other reported measurements of indomethacin $\mathrm{p} K_{\mathrm{a}}$ differ considerably $(4.01+/-0.09, \mathrm{l}=0.05 \mathrm{M}$, $25^{\circ} \mathrm{C}, \mathrm{CE}$ procedure [30]), (4.17, I=0.5 M, $25^{\circ} \mathrm{C}$ [31], (4.5, conditions not described [29]). The effects of aggregation should be less apparent in UV-metric $\mathrm{p} K_{\mathrm{a}}$ measurement, where the sample concentration is around $30 \mu \mathrm{M}$.

In parallel with these attempts to measure indomethacin $\mathrm{p} K_{\mathrm{a}}$ by $\mathrm{pH}$-metric titration it was observed during the solubility measurements that indomethacin did not fully dissolve at $\mathrm{pH} 9$ in the presence of 0.15 $\mathrm{M} \mathrm{KCl}$, which would be the case if the potassium salt of indomethacin was poorly soluble. It is important in CheqSol experiments that the sample is fully dissolved in ionised form at the start of the experiment and that no precipitated salt is present [26]. It was found that indomethacin did dissolve when solutions were prepared in deionised water adjusted to $\mathrm{pH} 9$, and the subsequent solubility measurements were therefore done in a low ionic strength background.

In order that the $\mathrm{p} K_{\mathrm{a}}$ value used in the solubility data sets were collected under similar conditions, it was measured in $\mathrm{pH}$-adjusted deionised water (average ionic strength $=0.058 \mathrm{M}$ ) by a UV-metric method. The carboxylic acid in indomethacin is not part of a chromophore but a small change in absorbance vs. $\mathrm{pH}$ was observed, and this was sufficient for reliable measurements to be made.

It is understood that $\mathrm{pH}$-metric experiments done at low ionic strength are susceptible to $\mathrm{pH}$ electrode calibration errors but these errors are most apparent at pH below 3 and above 11, and will have little effect on the solubility measurements reported here in which all relevant data were between $\mathrm{pH} 4$ and 9 .

\section{Results and Discussion}

\section{Evaluating the outlying published result}

The starting point for this research was to discover why a value of $410 \mu \mathrm{g} / \mathrm{mL}$ for solubility measured by CheqSol was so different from other reported values. 
The first step was to re-examine the data from which this result was derived. This experiment used a standard template for measurement of solubility of a monoprotic weak acid, which includes a dissolution phase wherein the sample solution is held at $\mathrm{pH} 12$ for several minutes. The sample will be fully ionised at this $\mathrm{pH}$ and is expected to dissolve in aqueous solution. Although an experiment starting at lower pH (e.g. between 7 and 10) would similarly ensure the compound is fully ionised, a value of 12 is normally chosen because water has a high buffer capacity at this $\mathrm{pH}$ and therefore resists the sample's tendency to drag the $\mathrm{pH}$ down as it dissolves, helping to ensure complete dissolution of the sample. The existence of titration data between the $\mathrm{pH}$ of sample dissolution and the $\mathrm{pH}$ of precipitation generally improves the quality of CheqSol experiments because it aids the calculation of acidity error and concentration factor, and may in some circumstances provide experimental verification of the sample's $\mathrm{p} K_{\mathrm{a}}$.

A Curve Fitting experiment was then run at $25{ }^{\circ} \mathrm{C}$ in $0.15 \mathrm{M} \mathrm{KCl}$ solution on the SiriusT3, starting at low $\mathrm{pH}$ where the indomethacin was present as a suspension of crystalline solid as obtained from the manufacturer. The suspension was titrated slowly with $\mathrm{KOH}$ solution and a Precipitation Bjerrum Curve was calculated from the $\mathrm{pH}$ measured as the sample dissolved (Figure 2). Although the data below $\mathrm{pH} 3$ deviates above a mean molecular charge of 0 and may indicate an electrode calibration error, this deviation occurs in a region where the sample is not undergoing ionization, and has no effect on the data above $\mathrm{pH}$ 3. It is, however significant that unionised indomethacin is poorly wettable and tends to float, which led to variable data quality. A result of $3.3 \mu \mathrm{g} / \mathrm{mL}$ was determined from the data points between the vertical red lines by the Curve Fitting procedure described below in the section "Investigating the intrinsic solubility of indomethacin"; this value is close to the values listed in Table 1.

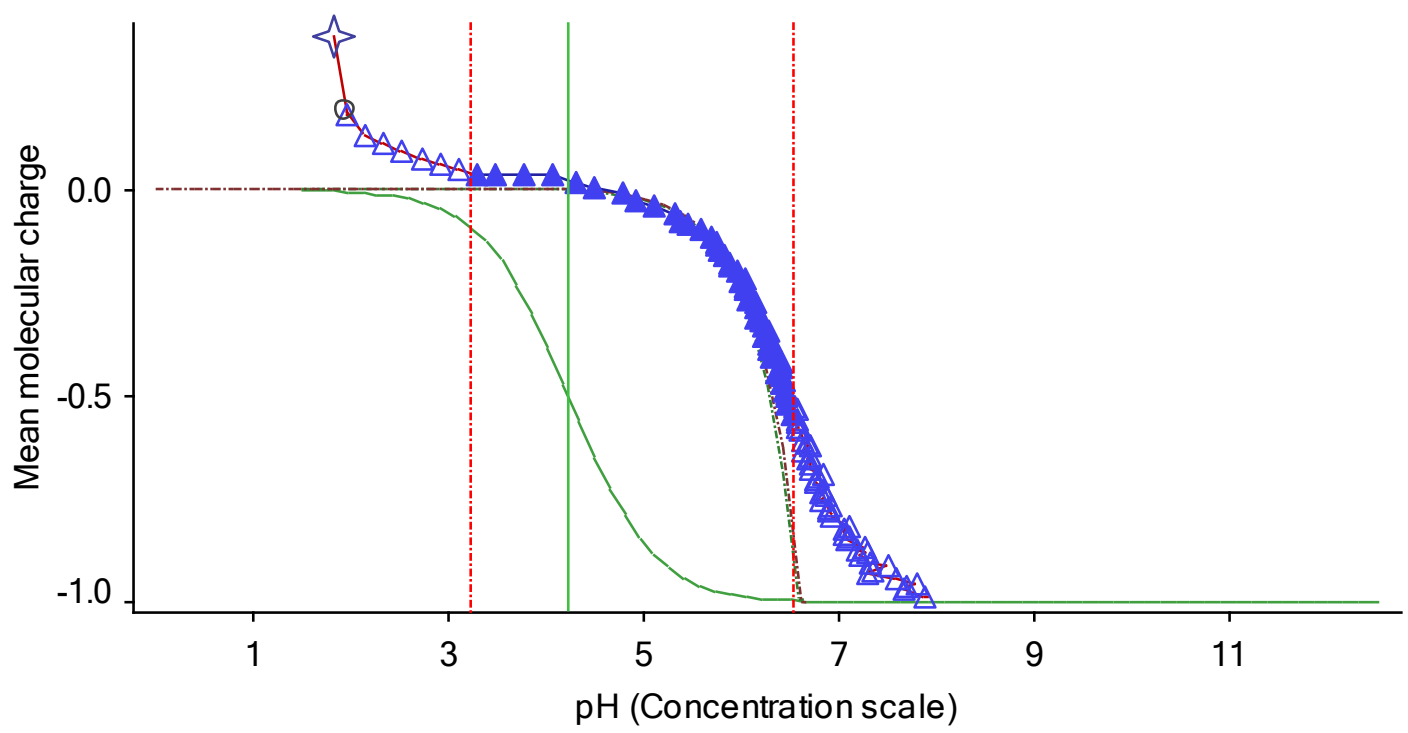

Figure 2. Curve Fitting experiment to determine the solubility of indomethacin; $3.8 \mathrm{mg}$ of indomethacin in $1.5 \mathrm{~mL}$ of $0.15 \mathrm{M} \mathrm{KCl}$, titrated with $0.5 \mathrm{M} \mathrm{KOH}$ at $25^{\circ} \mathrm{C}$. The solid blue triangles denote data points that are included in the Curve Fitting calculation. Unfilled triangles are excluded.

The comparison of solubilities measured in two experiments done in opposite $\mathrm{pH}$ directions provides a quick way to check for metastable behaviour of the solid state after precipitation. However a solubility of $410 \mu \mathrm{g} / \mathrm{mL}$ seemed too high to represent the solubility of a polymorphic form of indomethacin. Subsequent analysis of the data from the " $410 \mu \mathrm{g} / \mathrm{mL}$ " experiment indicated that the sample chased equilibrium during the assay, indicating that this result is not likely to correspond to an amorphous form. 
A careful literature search revealed that indomethacin can undergo base-catalysed hydrolysis [32] and it is shown here that it rapidly decomposes at $\mathrm{pH} 12$ to $p$-chlorobenzoic acid and 5-methoxy-2-methyl-3indoleacetic acid (1). It is therefore likely that the result of $410 \mu \mathrm{g} / \mathrm{mL}$ is erroneous, and that the species that was observed to chase equilibrium during the CheqSol assay was the least soluble of these two decomposition products. This decomposition is illustrated in Figure 1.

The experimental work now proceeded in two stages: a study to investigate the decomposition of indomethacin and a series of new CheqSol experiments to re-investigate the intrinsic solubility of indomethacin.

\section{Investigating the decomposition of indomethacin at high $\mathrm{pH}$}

The " $410 \mu \mathrm{g} / \mathrm{mL}$ " solubility experiment was repeated using the Sirius GLpKa, which provides $15 \mathrm{~mL}$ of solution containing $20 \mathrm{mg}$ of solid for examination. NMR shows the presence of peaks representing $p$ chlorobenzoic acid and the substituted indole (1). Separation of these two compounds was attempted using column chromatography but did not succeed due to the high polarity of the compounds. Instead, methyl esters of the acids were formed and separation via column chromatography was successful. The ester of the indole product was subsequently hydrolysed back to the corresponding acid. These compounds were fully characterized, and it was found that indomethacin had decomposed into $p$-chlorobenzoic acid and the substituted indole (1) during the dissolution phase of the experiment (15-20 min).

The $\mathrm{p} K_{\mathrm{a}}$ values of $p$-chlorobenzoic acid (3.75) and the substituted indole 1 (4.42) were measured. For an experiment at $10 \mathrm{mM}$ concentration, no precipitate was found for the indole (1), and its kinetic solubility was therefore expected to be higher than $10 \mathrm{mM}$. Using the measured value for the $\mathrm{p} K_{\mathrm{a}}$ of $p$-chlorobenzoic acid, the initial indomethacin decomposition CheqSol experiment was reanalysed and an accurate value for the solubility of $p$-chlorobenzoic acid was determined ( $302 \mu \mathrm{M} ; 42.4 \mu \mathrm{g} / \mathrm{mL}$ ). This was possible because the indole (1) has a much higher solubility than the concentration present in the experiment. The nature of the precipitate was established as $p$-chlorobenzoic acid. Details of the decomposition study and NMR results are given in the Appendix.

A re-analysis of the Bjerrum titration curve of the " $410 \mu \mathrm{g} / \mathrm{mL}$ " experiment leads to a conclusion that is consistent with the hypothesis that decomposition had occurred. Figure 3 shows that twice as many protons were lost from the added acid as was expected. This arises from the fact that twice as much base has been added as would be necessary for the concentration of monoprotic indomethacin introduced in the experiment, thus suggesting that two acidic protons are present for each sample molecule. If the calculation is modified to account for the presence of two weak acids, namely the poorly soluble $p$ chlorobenzoic acid that precipitated and the substituted indole (1) that remained in solution, then the calculated curve representing $p$-chlorobenzoic acid fits the experimental one (Figure 4). 


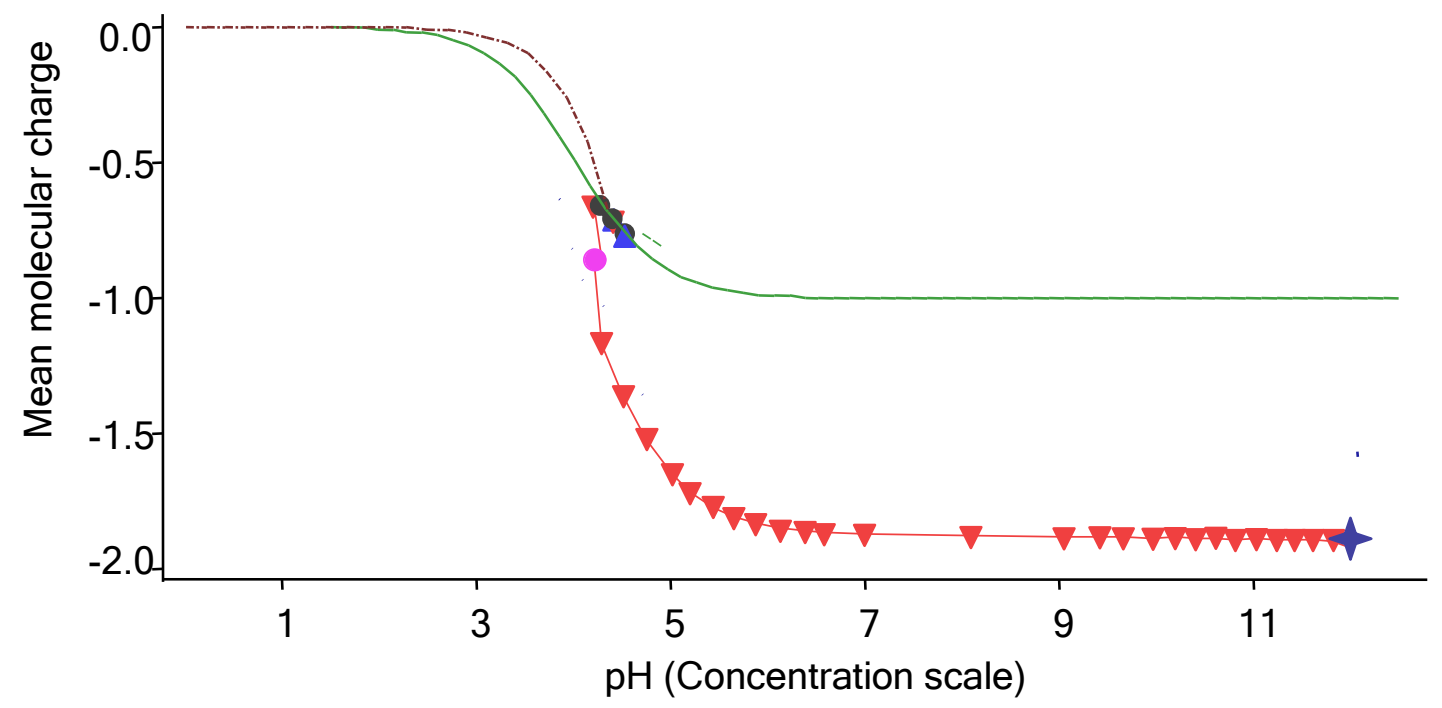

Figure 3. CheqSol solubility Bjerrum curve for indomethacin starting from $\mathrm{pH} 12$. The blue star indicates the starting point of the titration. The pink circle indicates the onset of precipitation. The Mean molecular charge value of -2 is consistent with the presence of two titratable acids.

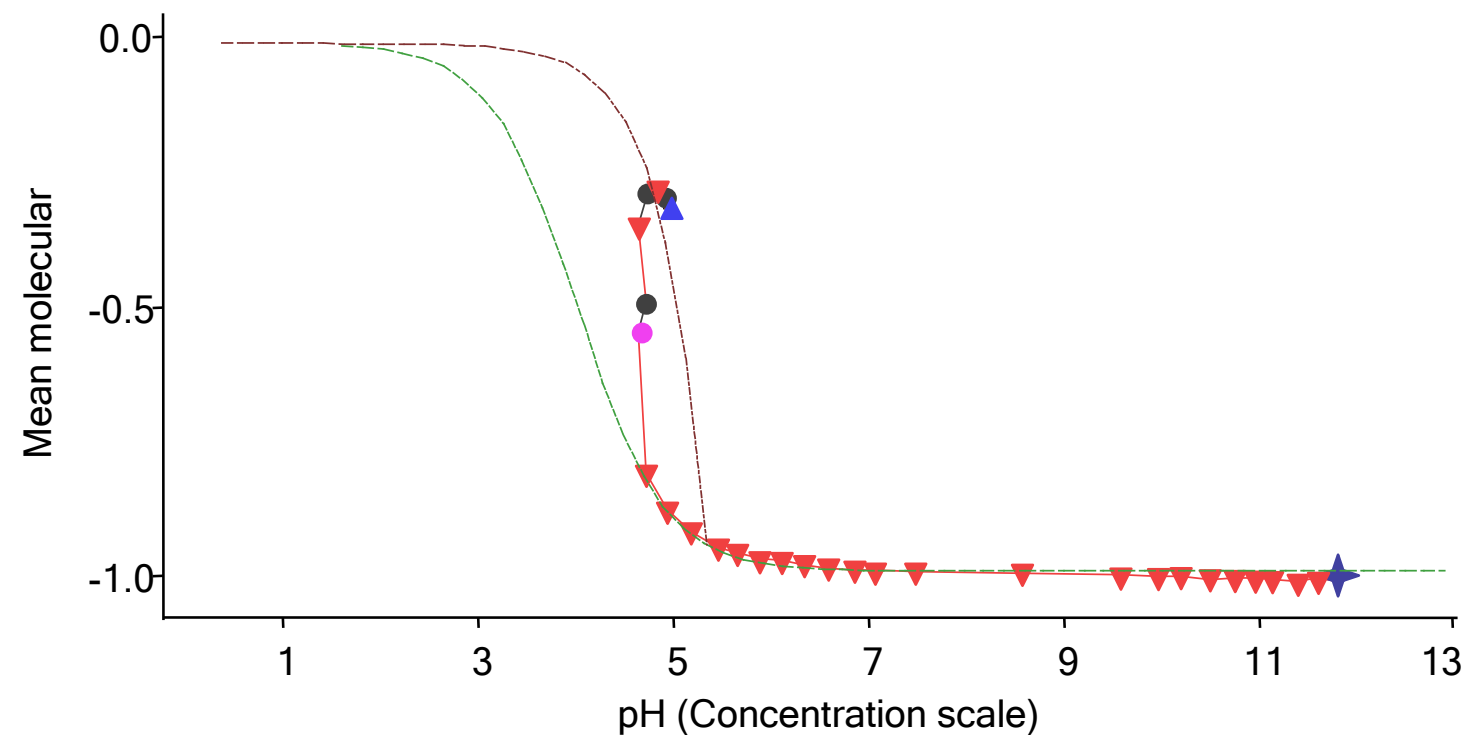

Figure 4. CheqSol solubility Bjerrum curve for indomethacin starting from $\mathrm{pH} 12$. The settings were modified into an assay for $p$-chlorobenzoic acid in the presence of one equivalent of the substituted indole 1 . Using these settings, a solubility result showing good agreement with the reported intrinsic solubility of $p$-chlorobenzoic acid was obtained.

Investigating the intrinsic solubility of indomethacin

A new series of CheqSol and Curve Fitting experiments was conducted to investigate the intrinsic solubility of indomethacin. To check for stability, solutions of indomethacin were prepared at pH 7.4, 9, 12 and $>12$ and stored for 3 hours, and then compared by HPLC/UV. Sharp peaks after 4.2 minutes were observed for the solutions at pH 7.4 and 9. However the peaks occurred after 2.8 minutes for the solutions prepared at higher $\mathrm{pH}$, suggesting that the composition of the solution was significantly different to the 
composition of the solutions prepared at lower $\mathrm{pH}$. With this evidence it was decided that decomposition could be avoided if experiments started at a pH of about 9.

All experiments were conducted at $25 \pm 0.5{ }^{\circ} \mathrm{C}$. Samples of indomethacin between $2 \pm 0.3 \mathrm{mg}$ were weighed into glass vials. $50 \mu \mathrm{L}$ of DMSO was added manually to aid dissolution and the vials were then placed on the Sirius T3 instrument, which added $1.5 \mathrm{~mL}$ of deionised water and then raised the $\mathrm{pH}$ to between 9.03 and 9.39 by adding about $10 \mu \mathrm{L}$ of $0.5 \mathrm{M} \mathrm{KOH}$ solution. In our experience the inclusion of 50 $\mu \mathrm{L}$ DMSO in the sample solution (corresponding to a DMSO concentration of about $2 \% \mathrm{v} / \mathrm{v}$ ) does not alter significantly the measured solubility values of most compounds. The vial plus contents was then sonicated for 5 minutes to ensure complete dissolution of the indomethacin in ionised form. The solution was then titrated with $0.5 \mathrm{M} \mathrm{HCl}$ until the onset of precipitation, which was detected by an in-situ UV probe. The concentration of neutral indomethacin in solution at the onset of precipitation is referred to as the kinetic solubility. After precipitation the experiments followed CheqSol or Curve Fitting protocols, which are described elsewhere [28]. Results of these solubility measurements are listed in Table 2.

Table 2. Results of experiments to measure solubility of indomethacin. Log $S$ refers to the logarithm to base 10 of the solubility in units of molarity.

\begin{tabular}{|c|c|c|c|c|c|c|c|c|c|c|}
\hline \multirow[t]{2}{*}{ Figure } & \multirow[t]{2}{*}{ Description } & \multirow{2}{*}{ Ionic strength } & \multirow[t]{2}{*}{ pKa } & & \multicolumn{2}{|c|}{ Kinetic } & \multicolumn{2}{|c|}{ Amorphous } & \multicolumn{2}{|c|}{ Intrinsic } \\
\hline & & & & & $\log S$ & $\mu \mathrm{g} / \mathrm{mL}$ & $\log S$ & $\mu \mathrm{g} / \mathrm{mL}$ & $\log S$ & $\mu \mathrm{g} / \mathrm{mL}$ \\
\hline 1 & $\begin{array}{l}\text { Curve-Fitting, pH2 up. } \\
\text { Original solid ( } 3.8 \mathrm{mg} \text { ) } \\
\text { dissolved during } \\
\text { experiment. }\end{array}$ & $0.157 \mathrm{M}$ & 4.22 & $(n=1)$ & & & & & -5.0 & 3.3 \\
\hline \multirow[t]{2}{*}{5} & $\begin{array}{l}\text { CheqSol pH9 down. } 2 \mathrm{mg} \\
+50 \mu \mathrm{L} \text { DMSO } \\
\end{array}$ & $0.0065 \mathrm{M}$ & 4.13 & $\begin{array}{l}\text { Average } \\
(\mathrm{n}=4)\end{array}$ & -3.6 & 76.9 & & & -4.6 & 8.8 \\
\hline & & & & Std. Dev. & 0.1 & 8.3 & & & 0.1 & 1.7 \\
\hline \multirow[t]{2}{*}{7} & $\begin{array}{l}\text { Curve Fitting, pH9 down. } \\
2 \mathrm{mg}+50 \mu \mathrm{L} \text { DMSO }\end{array}$ & $0.004 \mathrm{M}$ & 4.13 & $\begin{array}{l}\text { Average } \\
(\mathrm{n}=3)\end{array}$ & -3.7 & 68.7 & -3.7 & 79.8 & & \\
\hline & & & & Std. Dev. & 0.0 & 5.4 & 0.0 & 5.8 & & \\
\hline 8 & $\begin{array}{l}\text { Curve Fitting, pH9 down. } \\
2 \mathrm{mg}+50 \mu \mathrm{L} \text { DMSO }\end{array}$ & $0.004 \mathrm{M}$ & 4.13 & $(n=1)$ & -3.7 & 72.1 & & & -4.4 & 13.2 \\
\hline
\end{tabular}

The system chased equilibrium during the latter stages of all CheqSol experiments, suggesting that the precipitated material had crystallized. In one Cheqsol experiment, a few crystals of the original solid were added after the system had begun chasing equilibrium but there was no obvious shift in solubility, suggesting that the system was measuring the same polymorphic form.

In all of the CheqSol experiments the indomethacin precipitated initially in a form with mean kinetic solubility of $77 \mu \mathrm{g} / \mathrm{mL}$ that endured for between 5 and 15 minutes before converting to a form with mean intrinsic solubility of $8.8 \mu \mathrm{g} / \mathrm{mL}(\mathrm{n}=4)$. By analogy with published studies [33] it is likely that the initial precipitation is a Liquid-Liquid Phase Separation (LLPS) in which a disordered amorphous solid state is created that later crystallizes. This process is summarised in Figures 5 and 6 . Although the value of 8.8 $\mathrm{\mu g} / \mathrm{mL}$ was reproducibly measured in four experiments, it is not possible to claim that it represents the solubility of the least soluble polymorph. The effects of possible aggregation were not modelled in the software. There was $50 \mu \mathrm{L}$ of DMSO present in each experiment, which may affect the result and the crystal form. The Curve Fitting experiment starting at low pH with the original solid (Figure 1) determined a solubility of $3.3 \mu \mathrm{g} / \mathrm{mL}$, and other workers have reported lower values (Table 1). It could be useful in the future to re-measure the solubility in experiments with longer duration (e.g. 24 hours) to check for further 
conversion to a less soluble form; such changes have occasionally been observed in the Sirius laboratory and are described in Figure 6.



Figure 5. CheqSol solubility Bjerrum curve for indomethacin starting from $\mathrm{pH}$ 9. The blue star denotes the start of the experiment. The red triangles denote the addition of $\mathrm{HCl}$ titrant. The pink circle indicates the onset of precipitation, and lies on the green line representing the solubility of the initial precipitated form.

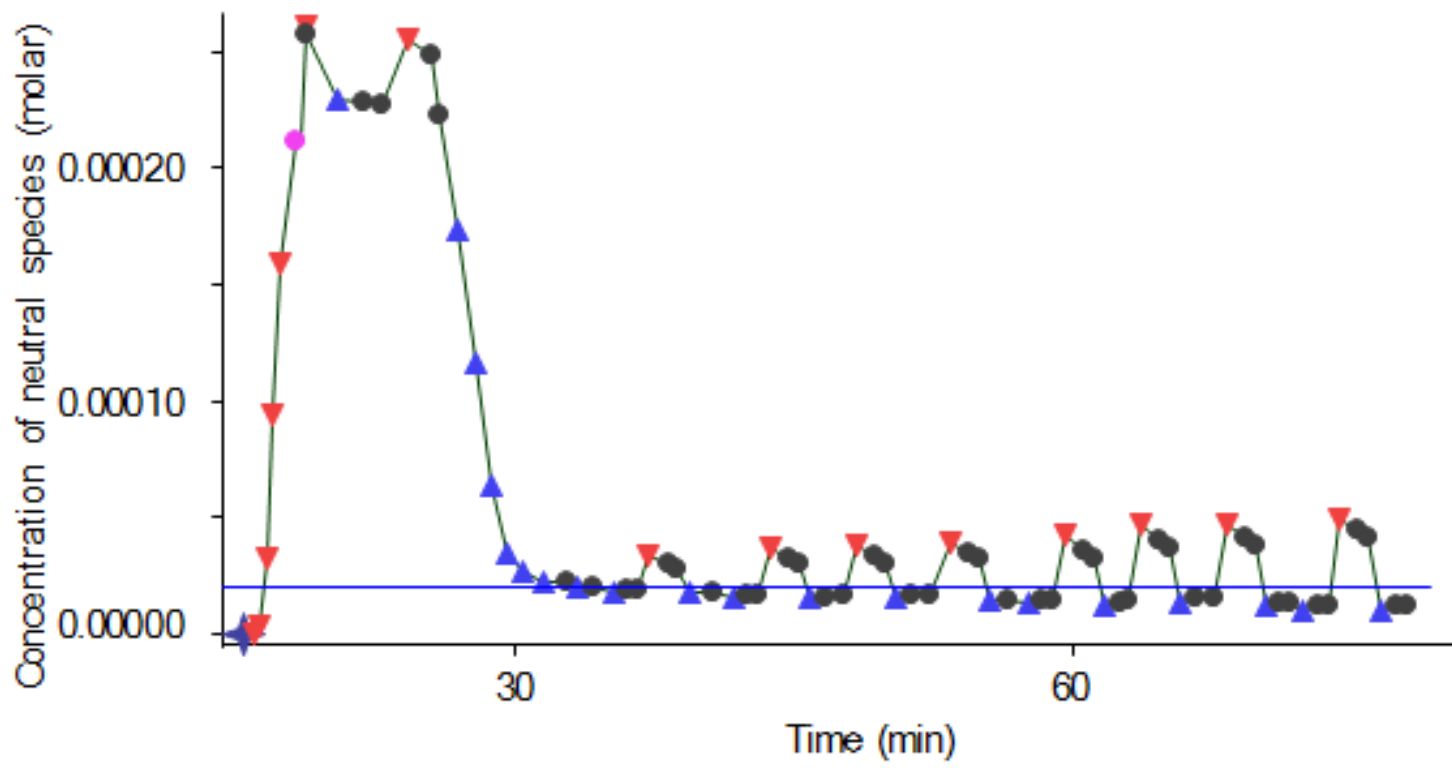

Figure 6. Data from Figure 5 re-plotted to show the concentrations of the initial precipitated form (plateau on left hand side) and the crystalline form (points from 35 minutes onwards), to which a solid blue line representing the intrinsic solubility has been fitted. The changes in magnitude of the concentration changes associated with the lower plateau may indicate that crystals are consolidating by Ostwald ripening. Although not evident here, CheqSol experiments with other samples sometimes show concentrations dropping to a lower plateau after longer times, suggesting that a metastable crystalline form has converted to a more stable crystalline form.

By contrast the precipitated sample persisted in the higher solubility form throughout three Curve Fitting experiments, as shown in Figure 7. It may be useful to speculate why the sample remained amorphous in the Curve Fitting experiments but crystallized in the CheqSol. In Curve Fitting experiments pH is adjusted in one direction only and this often allows the sample to persist in the amorphous state. In 
CheqSol experiments, successive aliquots of acid and base are added and it is believed this may stimulate the onset of crystallization after a short amorphous period. Although the sample remained amorphous during three Curve Fitting experiments, it converted soon after precipitation in a fourth experiment to a less soluble form, as shown in Figure 8. It is not understood why this conversion took place.

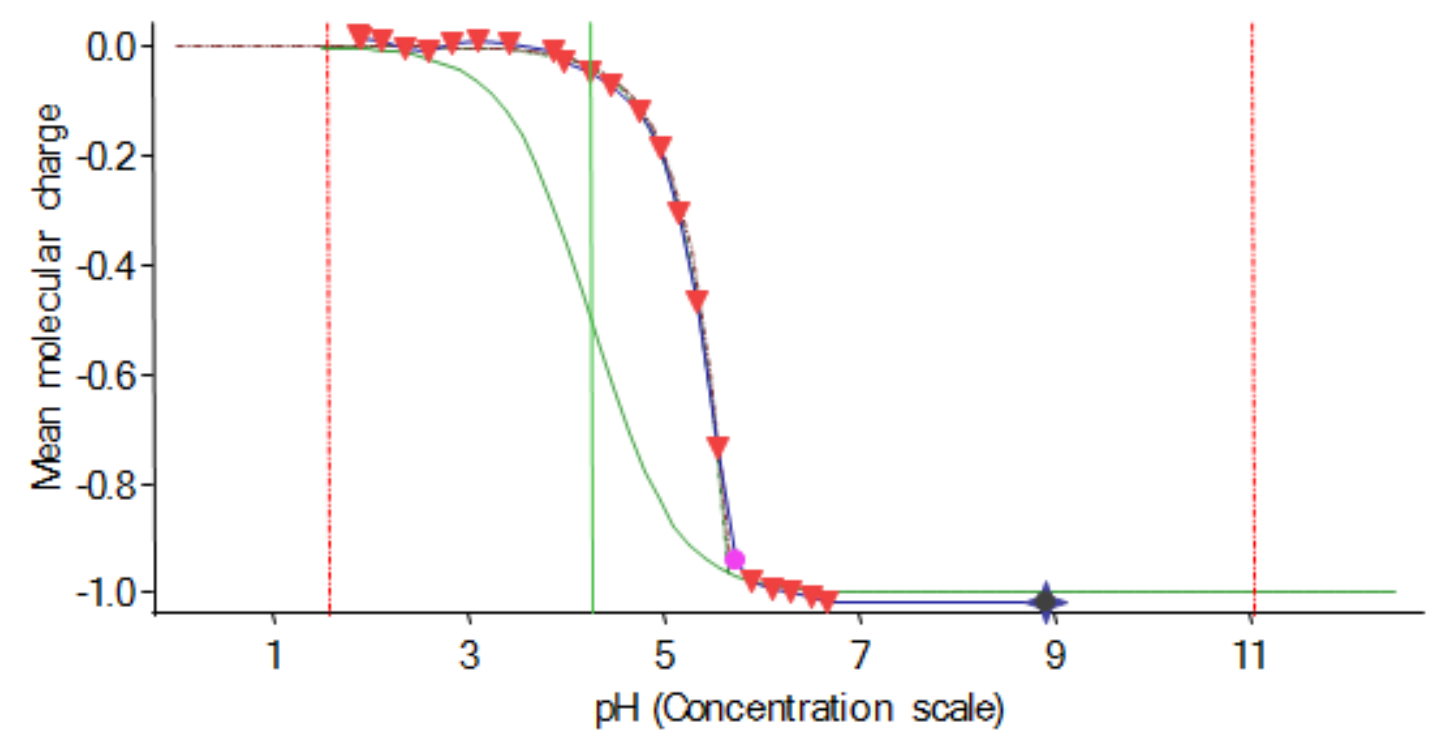

Figure 7. Curve Fitting experiment in which indomethacin persisted in a form that is probably amorphous.

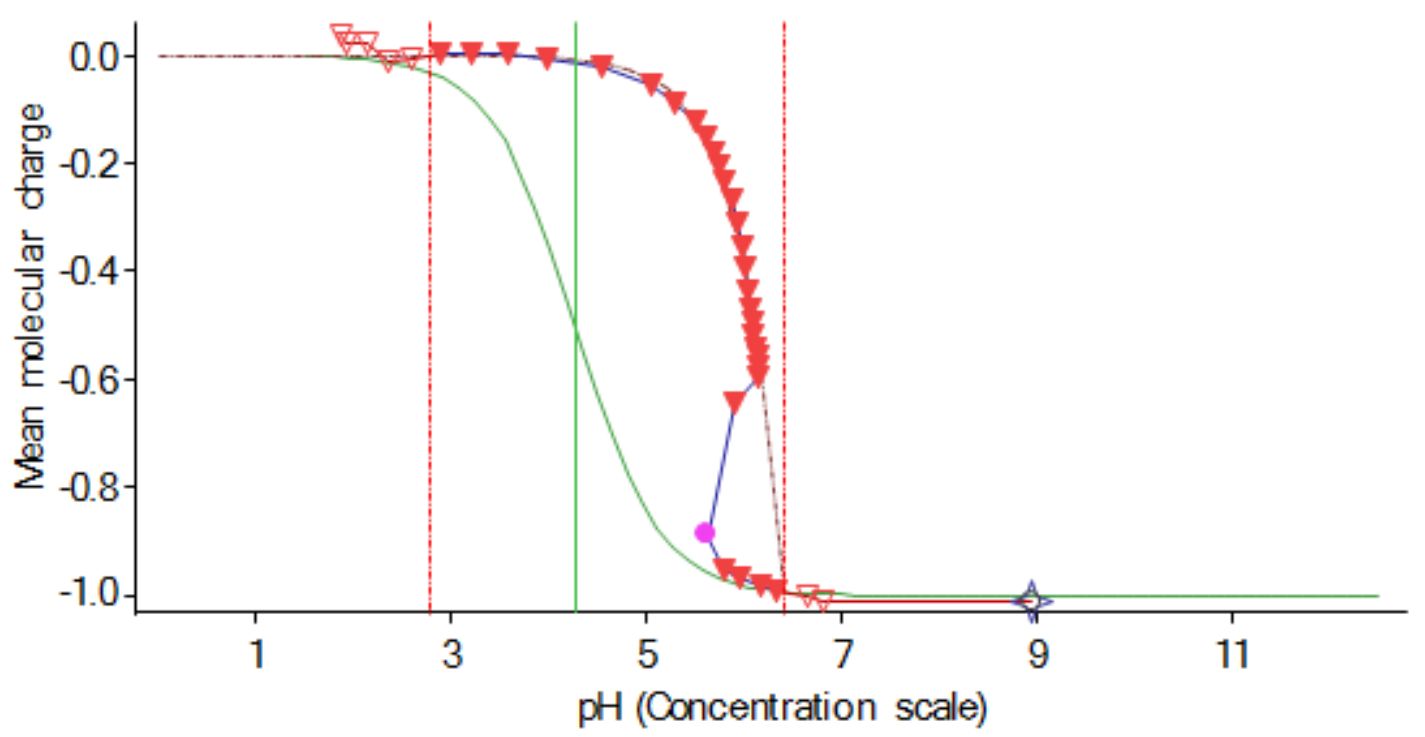

Figure 8. Curve Fitting experiment in which indomethacin converted soon after precipitation a form that is probably amorphous to a form with lower solubility.

It is important to point out that the Sirius Curve Fitting protocol differs from the Pion pSOL method [34]. In the pSOL method the solubility is calculated using an approach based on mass balance expressions constructed from the equilibrium equations and constants which iteratively derives the concentrations of all species present in solution and those which have precipitated. In the Sirius Curve Fitting method, samples are dissolved in ionised form and the solutions are titrated with acid or base towards the $\mathrm{pH}$ where the samples are in neutral form. The solution is a user-supervised automated on-screen graphics exercise in which the user selects the data points to include, and a theoretical Bjerrum curve representing the 
precipitation and calculated from the $\mathrm{p} K_{\mathrm{a}}$ and proposed solubility result is manually fitted to the selected data points. Data collection for Curve Fitting experiments is fast for compounds that precipitate in the amorphous (i.e. LLPS) form. This is because the so-called precipitation is actually a phase separation between an aqueous solution and a liquid or supercooled liquid phase. The pH quickly reaches a stable value after each addition of titrant, and the data generally fits the theoretical model well. Curve Fitting experiments are not suitable for compounds that quickly crystallise after precipitation because it may take many minutes for the $\mathrm{pH}$ to reach a stable value after each addition of titrant. These compounds are measured by the CheqSol method. Indomethacin is an unusual compound because it tends to remain in amorphous form during Curve Fitting experiments yet quickly converts to a crystalline form during CheqSol experiments.

\section{Conclusions}

Indomethacin decomposes rapidly at $\mathrm{pH}$ 12. This invalidates measurements of its solubility that involved any exposure to high $\mathrm{pH}$ conditions, and illustrates the importance of selecting appropriate assay conditions when analysing acid- or base-labile molecules using titration methods. Any unexpectedly large mean molecular charge values should be investigated, as they may suggest the occurrence of decomposition. It is shown that in some cases CheqSol assays can be carried out successfully even for $\mathrm{pH}$ unstable compounds if mild starting conditions are utilised. Indomethacin is stable at pH 9. A value of 8.8 $\mathrm{\mu g} / \mathrm{mL}$ for the intrinsic solubility of indomethacin was measured in experiments in which all data was collected at $\mathrm{pH} 9$ or below; however, this result may not represent the least soluble form. These experiments also provided strong evidence for the existence of a form of indomethacin with a solubility of about $77 \mu \mathrm{g} / \mathrm{mL}$, which persisted before crystallization for between 5 and 15 minutes.

The authors would like to suggest the following topics for future research. Any one of the following would be interesting: to create additional software for calculating solubility results from the $\mathrm{pH}$-metric CheqSol data that includes equilibrium expressions to describe aggregation; to run the CheqSol experiments for longer times in case the form with solubility of $8.8 \mu \mathrm{g} / \mathrm{mL}$ converts to a less soluble form; to examine the precipitates with a polarising light microscope or other tools to provide evidence of their amorphous or crystalline form; to identify a target $\mathrm{pH}$ at which indomethacin precipitates as the $\mathrm{pH}$ is lowered and then to run controlled supersaturation experiments at higher $\mathrm{pH}$ to investigate the duration of supersaturation and the induction time when a form change occurred.

Who did what: Sam Judge and Louise Towes ran $p K_{a}$ and solubility measurements using the SiriusT3. Darren Matthews ran HPLC experiments to validate the sample integrity. Bruno Falcone and Jonathan Goodman characterised the decomposition of indomethacin and measured the $p K_{a}$ and solubility of $p$-chlorobenzoic acid and the substituted indole (1). John Dearden encouraged the other authors to write this paper and provided valuable literature searches and insights. John Comer planned the solubility investigations, created the Figures and wrote or edited the text.

\section{References}

[1] H. Yamamoto. Chem. Pharm. Bull. 16(1) (1968) 17-19.

[2] L. Borka. Acta Pharm. Suecica. 11(3) (1974) 295-303.

[3] S-Y Lin. J Pharm Sci. 81(6) (1992) 572-576.

[4] N. Kaneniwa, M. Otsuka, T. Hayashi. Chem. Pharm. Bull. 33(8) (1985) 3447-3455.

[5] V. Andronis, G. Zografi. J. Non-Cryst. Solids. 271(3) (2000) 236-248.

[6] J.M. Aceves-Hernandez, I. Nicolás-Vázquez, F.J. Aceves, J. Hinojosa-Torres, M. Paz, V.M. Castaño. J. Pharm. Sci. 98(7) (2009) 2448-2463. 
[7] C. Aubrey-Medendorp, M.J. Swadley, T. Li. Pharm. Res. 25(4) (2008) 953-959.

[8] N. Hamdi, Y. Feutelais, N. Yagoubi, D. de Girolamo, B. Legendre. J. Therm. Anal. Cal. 76 (2004) 9851001.

[9] B.C. Hancock, M. Parks. Pharm. Res. 17(4) (2000) 397-403.

[10] S.B. Murdande, M.J. Pikal, R.M. Shanker, R.H. Bogner. J. Pharm. Sci. 99(3) (2010) 1254-1264.

[11] D. Iohara, F. Hirayama, T. Ishiguro, H. Arima, K. Uekama. Int. J. Pharm. 354(1-2) (2008) 70-76.

[12] M. Otsuka, T. Matsumoto, N. Kaneniwa. Chem. Pharm. Bull. 34(4) (1986) 1784-1793.

[13] A. Rezaei Mokarram, A. Kebriaee Zadeh, M. Keshavarz, A. Ahmadi, B. Mohtat. DARU J. Pharm Sci. 18(3) (2010) 185-192.

[14] T. Ito, T. Sugafuji, M. Maruyama, Y. Ohwa, T. Takahashi. J. Supramol. Chem. 1(4-6) (2001) $217-219$.

[15] O.A. Deshpande, V.B. Yadav. Int. J. Chem.Tech. Res. 1(4) (2009) 1312-1317.

[16] S.H. Yalkowsky, R.M. Dannenfelser. AQUASOL Database of Aqueous Solubility, version 5, College of Pharmacy, University of Arizona, Tucson, AZ, USA, 1992.

[17] F. Martínez, M.A. Peña, P. Bustamante. Fluid Phase Equilib. 308(1-2) (2011) 98-106.

[18] A. Nokhodchi. J. Pharm. Pharmaceu.t Sci. 8(1) (2005) 18-25.

[19] C.A.S. Bergström, M. Strafford, L. Lazorova, A. Avdeef, K. Luthman, P. Artursson. J. Med. Chem. 46(4) (2003) 558-570.

[20] S. Muchtar, M. Abdulrazik, J. Frucht-Pery, S. Benita. J. Control. Release 44(1) (1997) 55-64.

[21] S. Jambhekar, R. Casella, T. Maher. Int. J. Pharm. 270(1-2) (2004) 149-166.

[22] R. Bodmeier, H. Chen. J. Control. Release. 12(3) (1990) 223-233.

[23] M. Hewitt, M.T. Cronin, S.J. Enoch, J.C. Madden, D.W. Roberts, J.C. Dearden. J. Chem. Inf. Model. 49(11) (2009) 2572-87.

[24] A. Llinas, R.C. Glen, J.M. Goodman. J. Chem. Inf. Model. 48(7) (2008) 1289-303.

[25] A.J. Hopfinger, E.X. Esposito, A. Llinàs, R.C. Glen, J.M. Goodman. J. Chem. Inf. Model. 49(1) (2009) 1-5.

[26] M. Stuart, K. Box. Anal. Chem. 77(4) (2005) 983-990.

[27] K.J. Box, G. Völgyi, E. Baka, M. Stuart, K. Takács-Novák, J.E.A. Comer. J. Pharm. Sci. 95(6) (2006) 1298-1307.

[28] K. Box, J.E. Comer, T. Gravestock, M. Stuart. Chem. Biodiversity 6(11) (2009) 1767-1788.

[29] A. Fini, G. Fazio, G. Feroci. Int. J. Pharm. 126 (1995) 95-102.

[30] M. Shalaeva, J. Kenseth, F. Lombardo, A. Bastin, A. J. Pharm. Sci. 97(7) (2008) 2581-2606.

[31] K.G. Mooney, M.A. Mintun, K.J. Himmelstein, V.J. Stella. J. Pharm. Sci. 70(1) (1981) 13-22.

[32] B. Tsvetkova, I. Pencheva, A. Zlatkov, P. Peikov. Int. J. Pharm. Sci. 4(Supplement 3) (2012) 549.

[33] S.A. Raina, G.Z. Zhang, D.E. Alonzo, J. Wu,D. Zhu,N.D. Catron, Y. Gao, L.S. Taylor. J. Pharm. Sci. 2014, DOI: 10.1002/jps.23826

[34] A. Avdeef. Pharm. Pharmacol. Commun. 4 (1998) 165-178.

[35] M.Z. Southard, D.W. Green, V.J. Stella, K.J. Himmelstein. Pharm. Res. 9(1) (1992) 58-69.

[36] K. Okimoto, R.A. Rajewski, K. Uekama, J.A. Jona, V.J. Stella. Pharm. Res. 13(2) (1996) 256-64.

[37] C.M. Wassvik, A.G. Holmen, C.A. Bergstrom, I. Zamora, P. Artursson. Eur. J. Pharm. Sci. 29(3-4) (2006) 294-305.

[38] J.H. Fagerberg, O. Tsinman, N. Sun, K. Tsinman, A. Avdeef, C.A. Bergstrom. Mol. Pharm. 7(5) (2010) 1419-30.

[39] Simulations Plus, Inc. 42505 10th Street West Lancaster, CA 93534, USA. http://www.simulationsplus.com/

[40] StarDrop: Optibrium Ltd. 7221 Cambridge Research Park Beach Drive Cambridge CB25 9TL, UK. http://www.optibrium.com/starvue/index.php 
[41] CSlogWS: ChemSilico LLC, 48 Baldwin St. Tewksbury, MA 01876, USA. http://www.chemsilico.com/

[42] ALOGPS: I.V. Tetko, J. Gasteiger, R. Todeschini, A. Mauri, D. Livingstone, P. Ertl, V.A. Palyulin, E.V. Radchenko, N.S. Zefirov, A.S. Makarenko, V.Y. Tanchuk, V.V. Prokopenko. J. Comput. Aid. Mol. Des 19 (2005) 453-463.

[43] WSKOWWIN: http://www.epa.gov/oppt/exposure/pubs/episuite.htm

[44] WATERNT: http://www.epa.gov/oppt/exposure/pubs/episuite.htm 


\section{Appendix}

Indomethacin decomposition experiment

lonic strength adjusted water $(10 \mathrm{~mL}, 0.15 \mathrm{M} \mathrm{KCl})$ was added to indomethacin ( $130 \mathrm{mg}, 0.36 \mathrm{mmol})$. The $\mathrm{pH}$ was brought to 12 by addition of $\mathrm{KOH}$ solution $(1.73 \mathrm{~mL}, 0.5 \mathrm{M})$ and the solution was stirred for $40 \mathrm{~min}$ under nitrogen. The mixture was titrated towards low $\mathrm{pH}$ until precipitation was detected.

\section{Extraction of product of decomposition experiment}

The solution was brought to $\mathrm{pH} 1$ by addition of aqueous $\mathrm{HCl}(3 \mathrm{~N})$. The aqueous layer was extracted with EtOAc $(3 \times 25 \mathrm{~mL})$. The organic layers were combined, dried over $\mathrm{Na}_{2} \mathrm{SO}_{4}$ and the solvent was removed in vacuo to afford a white solid (100 $\mathrm{mg})$.

Identification of products of decomposition experiment

${ }^{1} \mathrm{H} \mathrm{NMR}\left(500 \mathrm{MHz}, \mathrm{CDCl}_{3}, \mathrm{~T}=298 \mathrm{~K}\right) \delta 7.99(2 \mathrm{H}, \mathrm{d}, J=8.5 \mathrm{~Hz}), 7.43(2 \mathrm{H}, \mathrm{d}, J=8.5 \mathrm{~Hz})$ corresponding to $p$ chlorobenzoic acid.

${ }^{1} \mathrm{H}$ NMR $\left(500 \mathrm{MHz}, \mathrm{CDCl}_{3}, \mathrm{~T}=298 \mathrm{~K}\right) \delta 7.76(1 \mathrm{H}, \mathrm{br}), 7.14(1 \mathrm{H}, \mathrm{d}, J=8.7 \mathrm{~Hz}), 6.98(1 \mathrm{H}, \mathrm{d}, J=2.2 \mathrm{~Hz}), 6.78$ $(1 \mathrm{H}, \mathrm{dd}, J=8.7,2.4 \mathrm{~Hz}), 3.84(3 \mathrm{H}, \mathrm{s}), 3.68(2 \mathrm{H}, \mathrm{s}), 2.37(3 \mathrm{H}, \mathrm{s})$ corresponding to the substituted indole (1).

LCMS Electrospray Ionisation: calc. for $[\mathrm{M}-\mathrm{H}]^{-}$218.08, found 218.4; calc. for $p$-chlorobenzoic acid $\mathrm{C}_{7} \mathrm{H}_{5}{ }^{35} \mathrm{ClO}_{2}[\mathrm{M}-\mathrm{H}]^{-}$154.99, found 155.2 (75\%); calc. for $p$-chlorobenzoic acid $\mathrm{C}_{7} \mathrm{H}_{5}{ }^{37} \mathrm{ClO}_{2}[\mathrm{M}-\mathrm{H}]^{-} 156.99$, found 157.2 (25\%).

\section{Esterification of decomposition products}

The mixture of decomposition products was dissolved in $\mathrm{MeOH}(5 \mathrm{~mL}) . \mathrm{HCl}(1 \mathrm{M}$ in $\mathrm{MeOH}, 1 \mathrm{~mL})$ was added and the mixture was heated under reflux for $3 \mathrm{~h}$, stirred at room temperature overnight, and heated under reflux again for $3.5 \mathrm{~h}$. The solvent was concentrated in vacuo. Purification by flash column chromatography $\left(\mathrm{SiO}_{2}\right.$, 20:1 40-60 petroleum ether/EtOAc for fraction I, and 4:1 40-60 petroleum ether / EtOAc for fraction II) afforded methyl $p$-chlorobenzoate (40 mg, fraction I), and (5-methoxy-2methyl-indol-3-yl) acetic acid methyl ester (2) (70 mg, fraction II).

${ }^{1} \mathrm{H}$ NMR $\left(500 \mathrm{MHz}_{\mathrm{CDCl}}, \mathrm{T}=298 \mathrm{~K}\right) \delta 7.92(1 \mathrm{H}, \mathrm{s}, \mathrm{NH}), 7.07(1 \mathrm{H}, \mathrm{d}, J=8.7 \mathrm{~Hz}, \mathrm{H} 7), 7.01(1 \mathrm{H}, \mathrm{d}, J=2.2 \mathrm{~Hz}$, H4), $6.78(1 \mathrm{H}, \mathrm{dd}, J=8.7,2.2 \mathrm{~Hz}, \mathrm{H} 6), 3.87(3 \mathrm{H}, \mathrm{s}, \mathrm{OMe}), 3.68(3 \mathrm{H}, \mathrm{s}, \mathrm{COOMe}), 3.68\left(2 \mathrm{H}, \mathrm{s}, \mathrm{CH}_{2}\right), 2.31(3 \mathrm{H}, \mathrm{s}$, C2- $\underline{-\mathrm{Me}})$.

${ }^{13} \mathrm{C}$ NMR (125 MHz, CDCl, $\left.\mathrm{T}=298 \mathrm{~K}\right) \delta 172.8$ (COO), 154.1 (C-5), 133.8 (C-2/3a/7a), 130.3 (C-2/3a/7a), 128.9 (C-2/3a/7a), 111.1 (C-7), 110.9 (C-6), 104.2 (C-3), 100.5 (C-4), 56.0 (OMe), 52.0 (COOMe), $30.3\left(\mathrm{CH}_{2}\right.$ ), 11.7 (Me).

Hydrolysis of 2

A mixture of 2 (640 mg, $2.75 \mathrm{mmol})$ and $\mathrm{LiOH} \bullet \mathrm{H}_{2} \mathrm{O}(1.15 \mathrm{~g}, 27.5 \mathrm{mmol})$ in 1:1 THF:water $(10 \mathrm{~mL})$ was stirred for $23 \mathrm{~h}$. Aqueous $\mathrm{HCl}(3 \mathrm{M}, 5 \mathrm{~mL})$ was added and the $\mathrm{pH}$ was brought to 4 . The solution was saturated with $\mathrm{NaCl}$ and extracted with EtOAc $(3 \times 25 \mathrm{~mL})$. The organic fractions were combined, dried over $\mathrm{Na}_{2} \mathrm{SO}_{4}$ and concentrated in vacuo. The product was recrystallised twice from hot ethanol to afford (5methoxy-2-methyl-indol-3-yl) acetic acid (5-Methoxy-2-methyl-3-indoleacetic acid, 1) (98 mg).

${ }^{1} \mathrm{H}$ NMR $\left(500 \mathrm{MHz}, \mathrm{CDCl}_{3}, \mathrm{~T}=298 \mathrm{~K}\right) \delta 7.72(1 \mathrm{H}, \mathrm{br}, \mathrm{NH}), 7.14(1 \mathrm{H}, \mathrm{d}, J=8.7 \mathrm{~Hz}, \mathrm{H} 7), 6.96(1 \mathrm{H}, \mathrm{d}$, $J=2.3 \mathrm{~Hz}, \mathrm{H} 4), 6.78(1 \mathrm{H}, \mathrm{dd}, J=8.7,2.4 \mathrm{~Hz}, \mathrm{H} 6), 3.84(3 \mathrm{H}, \mathrm{s}, \mathrm{OMe}), 3.65\left(2 \mathrm{H}, \mathrm{s}, \mathrm{CH}_{2}\right), 2.35(3 \mathrm{H}, \mathrm{s}, \mathrm{Me})$. 
${ }^{1} \mathrm{H}$ NMR $\left(500 \mathrm{MHz}, \mathrm{CD}_{3} \mathrm{OD}, \mathrm{T}=298 \mathrm{~K}\right) \delta 7.11(1 \mathrm{H}, \mathrm{d}, J=8.7 \mathrm{~Hz}, \mathrm{H} 7), 6.95(1 \mathrm{H}, \mathrm{d}, J=2.4 \mathrm{~Hz}, \mathrm{H} 4), 6.67(1 \mathrm{H}$, $\mathrm{dd}, J=8.7,2.4 \mathrm{~Hz}, \mathrm{H} 6), 3.79(3 \mathrm{H}, \mathrm{s}, \mathrm{OMe}), 3.61\left(2 \mathrm{H}, \mathrm{s}, \mathrm{CH}_{2}\right), 2.34(3 \mathrm{H}, \mathrm{s}, \mathrm{Me})$.

${ }^{13} \mathrm{C}$ NMR (125 MHz, CD OD, T = $\left.298 \mathrm{~K}\right) \delta 176.2$ (COO), 155.0 (C5), 135.0 (C2/3a/7a), 132.1 (C2/3a/7a), 130.2 (C2/3a/7a), 111.9 (C7), 111.2 (C6), 104.8 (C3), 101.2 (C4), 56.3 (OMe), $30.9\left(\mathrm{CH}_{2}\right), 11.4$ (Me).

(C2014 by the authors; licensee IAPC, Zagreb, Croatia. This article is an open-access article distributed under the terms and conditions of the Creative Commons Attribution license (http://creativecommons.org/licenses/by/3.0/) (cc)) EY 